\title{
Research and Practice of Project-Based Teaching and Examination Methods on Engineering Drawing for Excellent Class
}

\author{
Xiaolan Yang, Ting Zhang, Qilin Jiang \\ College of Mechanical Engineering, Nanjing Institute of Technology, Nanjing, 211167,China \\ email: yxhh001@163.com
}

Keywords: Excellent class; Engineering drawing; Basic capability; Project-based; Educational
practice

\begin{abstract}
For the status and problems in the teaching of the "excellent class", the project-based teaching plan is raised to develop the basic capability of engineering drawing ability for the "excellent class". Through project-based teaching, course teaching, homework, engineering drawing and other teaching links to arouse the interest of the students and mobilize their initiative, and the students' abilities to draw diagrams are improved effectively. These make the students have the really basic capabilities in engineering drawing which include knowledge and professionalism. It lays a solid foundation for the follow-up professional course learning. This educational practice can provide the beneficial reference to foster the basic capability of engineering drawing in regular class and other course reform.
\end{abstract}

\section{Introduction}

Faced with the new requests of enterprises for talents especially for the "excellent class", we will do the practice and exploration of Engineering Drawing, combined with the project-based teaching plan and reform of examination method.

\section{Building the project-based teaching model to foster the basic capability of engineering drawing for the excellent class}

For the course outline requirement of the "excellent class", the course content is divided into five parts, then the three goals: the ability, knowledge and professional quality corresponded to the engineering drawing are planed; based on professional direction, take the gear pump, plastic mould and such typical products as the carrier. According to project-based teaching methods, the engineering drawing and mapping are divided into 4 projects and 12 subprojects. The goals of each subproject are planed, which include the ability and the related support knowledge of the excellent engineers. The project-based teaching with engineering drawing and drill practice are formed, the model of project-based teaching with class-mapping of engineering drawing for the "excellent class" is summed up.

\section{Building a complete and comprehensive examination model}

The comprehensive examination method is established which includes course teaching (course demonstration, questions, practice), school assignment (the comment on the work), the reply of term end and written examination. The students' capability in reading and understanding technical drawings(the basic and profession reading and understanding technical drawings), drawing(freehand drawing, manual drawing, computer aided drawing), engineering drawing knowledge and the professional quality of studying performance and examination are all recorded in the whole course, then the comprehensive evaluation mechanism is formed[1,2].

\section{Building the new drawing model —_ drawing and design"}

The traditional drawing is that distribute the whole drawing body to the students, then they begin 
to draw after disassembling, this teaching method had the disadvantage of training and inspiring the students' learning initiative and creativity. A new design method is contemplated, and the now drawing method is as follow: the students are given the "incomplete" parts, and let them use the studied knowledge to design the missing parts. Although, the students' design maybe not exactly right firstly, it can increase the students' interests and participating motivation, at last the right and reasonable parts structure can be designed after the teacher's guidance.

\section{The reform and practice}

\section{The reform of project-based teaching method}

In the past, most of teaching programs are formulated and implemented based on the knowledge system of the course, and the content of courses are lack of the pertinence and practicality. It made the students in a passive learning state. The project-based teaching method is based on independently explore, and adopted the scientific method to promote the students actively constructing knowledge. The questions and tasks which need be solved are taken as the form of project to the students, and the students can draw up a plan independently or in a group under the teacher's guidance, and complete the project by the group collaboration. A teaching principle which regard the students as the main body and the teacher as the leading are formed. The student's main body consciousness is increased[3-5].

The goal of this reform is deal with the teaching status and existing problems of the "excellent class". "Project-based "teaching structure system is consisted by the basic project, the typical parts project, project CAD drawing and the drawing project (take the mould assembly drawing as an example).

This "project-based" course structure system is a teaching mode which dived by the project task and expanded the teaching process. It can let students understand the industry background and know the working characteristics of industry.

\section{The reform of the examination method}

The test method of "engineering drawing" has followed a mode which got scores by a piece of examination paper for years, this method can't comprehensively assessment the students' studied knowledge and ability and have disadvantage of training the comprehensive quality[6].

The comprehensive evaluation method which takes the course teaching(course demonstration, questions, practice) examination records as the reference and the school assignment examination(the comment on the work), the machine test, the reply of term end, terminal written examination as the basis is put forward by this passage. The students' capability in reading and understanding technical drawings(the basic and profession reading and understanding technical drawings), drawing(freehand drawing, manual drawing, computer aided drawing), engineering drawing knowledge and the professional quality of studying performance and examination are all recorded in the whole course, then the comprehensive evaluation mechanism is formed in the whole course.

On the basis of the course examination, the score of final exam is made up by four parts:

The homework scores(10\%)+ the machine test scores(20\%)+the reply of term end(10\%) + the written examination $(60 \%)=$ the total scores $(100 \%)$.

a. The homework scores: The full scores is 10. The full scores of the workbook is 6 and the full scores of the manual drawing is 4 .

b. The machine test: It is the computer graphics test and use the computer to draw, then the score is given by the teacher. The key point are the drawing speed and ability test of the parts. The full scores is 10 .

c. The reply of term end: Let the students extract the card, and there are questions on the card.

The key point are the basic knowledge and the ability test, and the full scores is 10 . 
d. The written examination: Use the closed-book exam at the end of the term, the test time are 2 hours, and the full scores is 60 .

The score of the course examination is not more than 5 points. It is the supplement of the above total score. The course examination included the questions, practice, only for the student who has good or bad performance to add or subtract points. The course questions are the tradition of every class, and this is a good prompting for the students to prepare lessons and listen carefully in class. The total score is not more than 100 points in the end.

The reply of term end is the assessed method which has the excellent results. It is shown as following:

a. Compared with the tradition exam method, the teachers and students change "back-to-back" for "face to face". Based on the reply, it can reflect the situation that the students use the knowledge and feedback out the problems in the teaching;

b. The reply questions cover wide range of knowledge. It involve the questions which the written examination didn't easy test, such as table lookup, the choose benchmark of dimension, the explaining of the technical requirements and other content. It can reflect students' comprehensive ability;

c. The reply method is flexible, and the choice examination questions are divided into A, B and C three tapes according to the complexity of the graphics. They are made into cards, and it is fairness for the students to select randomly the card to reply.

$\mathrm{d}$. The reply questions can exercise the students' language skills, and improve the strain capacity and humanistic quality. It is the effective method to reflect the quality education.

\section{The educational reform practice}

In the "excellent engineers education" training talent plan, the mould excellent class as the experimental unit is chosen, putting the drill project design into the practice, the comprehensive assessment is tracked and the work is carried fairly, equitably and publicly.

\section{The design of drill project}

This is the key to project-based teaching effect. The engineering drawing course requires students have strong space thinking ability, and the comprehensive use projection knowledge, the expression methods of the parts and other capacity. So project topics design should be suitable for professional development direction. The workload of the project should be moderate. The difficulty of the subject should be suitable. The ability of learning engineering drawing target, target of knowledge and the professional quality also need to take into account. Teachers must effectively cut and decompose the knowledge to make each sub-project of the project topics and appraisal target form, and appropriately guide students to practice according to the inspection target. The students' practice process is tracked, then in the maximum limit arouse and inspire students' enthusiasm of study and learning enthusiasm, so the interesting of the students is driven.

\section{Track the comprehensive assessment and carry the work fairly, equitably and publicly}

Responsibility of the teachers is the key link, and the record must be in time, in accuracy and in detail. Assessment should reflect the fairly, equitably and publicly. For example, the class examination records must record the classroom questioning and exercises timely, and students who has the best and worst performance must be announced. Take the homework grade as another example, most students in the class know which students are good or bad, and it is better to praise the excellent and thrash the backward students in time, and promote the middle students by seizing both sides students. Fair and public of examine to build up good class atmosphere. The good students have more enthusiasm in studying, and bad students study hard to catch up, which can promote the further improvement of the teaching effect. 


\section{Conclusion}

According to "excellent engineers education training plan", developing students' engineering drawing abilities includes the basic knowledge and professional quality, guiding students to have interest in training engineering drawing ability and inspiring their initiation. Develop the abilities of students to recognize drawing(basic reading drawing, professional reading drawing) and draw drawings effectively(freehand drawing, manual drawing, computer drawing). Students have the basic capability in engineering drawing like "excellent engineers". The reformation arrives at twice the result with half the effort.

According to "the project-based education teaching plan", the comprehensive evaluation method of engineering drawing curriculum is planned. The comprehensive evaluation method is formed by assessment records of course teaching(course demonstration, questions, practice), assessment of homework, computer graphics, reply and written examination of term end. The students' capability of reading and understanding technical drawings(the basic and profession reading and understanding technical drawings), drawing(freehand drawing, manual drawing. computer aided drawing), engineering drawing knowledge and the professional quality of studying performance and examination are all recorded in the whole course, and then the comprehensive evaluation mechanism is formed in the whole course. As practice comprehensive assessment, the drawing week matching the course examination is formulated(the self-examination, the group inter-examination and the reply), and it makes the students learn and makes the teachers teach in practice to guarantee the implementation of project-based educational teaching plan, and then the basic engineering drawing abilities and the training of the professional quality of students in "excellent class” have a great development.

\section{Acknowledgements}

This work is supported by teaching reform project of Nanjing Institute of Technology(JG201108).

\section{References}

[1] Nortel. Leveraging it to create an innovative, cooperative, student--centered curriculum[J]. Case study, Franklin, W.Olin College of Engineering, 2009.

[2] Fan. Zhang. German universities excellence review[J]. Comparative Education Reseacher, 2007, 12.

[3] Manli. Li. The unique way of cultivating excellent engineers[J]. University Education Sscience, 2010(2) 91-95.

[4] Kexiang. Wei, Yingchun. Liu, and Xinnian. Chen. Engineering application talents training practice teaching system of research and practice[J]. China University Teaching, 2011(1)74-76.

[5] Pingyuan. Xiong, Lixue Zhu and Xiaozheng. Yuan. Excellent engineers cultivation plan for the descriptive geometry and mechanical drawing teaching system[J] Science and Technology Information, 2011 (23) 35.

[6] Liangfeng. Zhang, Caiming $\mathrm{Fu}$ and Haoge Peng. Based on the developing great engineer machinery specialized curriculum teaching reform to explore[J]. Journal of Hunan Engineering Institute, 2011(4) 108-114. 